\title{
Hydrogen Bonds Sites of Amylose or Amylopectin from Starch at the ONION Level (B3LYP/6-311++G [d, p]: AM1)
}

\author{
Ablé Anoh Valentin, N’Guessan Boka Robert, Bamba El Hadji Sawaliho* \\ Laboratoire de Constitution et de Réaction de la Matière, UFR SSMT, Université Félix Houphouët-Boigny, Abidjan, Côte d'Ivoire \\ Email: ^bamba_el_hadji@yahoo.fr
}

How to cite this paper: Valentin, A.A., Robert, N.B. and Sawaliho, B. El H. (2021) Hydrogen Bonds Sites of Amylose or Amylopectin from Starch at the ONION Level (B3LYP/6-311++G [d, p]: AM1). Computational Chemistry, 9, 85-96.

https://doi.org/10.4236/cc.2021.91005

Received: December 16, 2020

Accepted: January 22, 2021

Published: January 25, 2021

Copyright (C) 2021 by author(s) and Scientific Research Publishing Inc. This work is licensed under the Creative Commons Attribution International License (CC BY 4.0).

http://creativecommons.org/licenses/by/4.0/

\section{Open Access}

\begin{abstract}
The research aims to help reduce the enormous post-harvest losses of rice or bananas in Cote d'Ivoire. It focuses on the breakdown mechanism of their starch. This process contributes to their decay. This study wants to elucidate it; to do this, it analyzes the tetra or penta saccharide reactions with the water or dioxide carbon. It calculates the geometric, energetic and spectroscopic parameters at the ONIOM level (B3LYP/6-311++G [d, p]: AM1). These quantities allow establishing that oxygen $\mathrm{O}_{2 \mathrm{sp}^{3}}$ represents the privileged hydrogen bond (HB) site for amylose with four or five D-glucose building blocks. They suggest $\mathrm{O}_{3 \mathrm{sp}^{3}}^{\prime}$ and $\mathrm{O}_{4 \mathrm{sp}^{3}}^{\prime}$ are respectively those of amylopectin when the latter consists of four and five D-glucose synthons. They prove that amylose deteriorates before it; the degradation of starch begins with its alteration into disaccharides. It continues with that of amylopectin into tri or tetra-saccharides with four or five building blocks.
\end{abstract}

\section{Keywords}

Hydrogen Bonds, Glucose, Amylose, Amylopectin

\section{Introduction}

Plantain bananas contribute to food security in Sub-Saharan Africa. It's an excellent source of energy and nutrients. It's part of the basic meal for one hundred million people at least [1]. In Côte d'Ivoire, its annual production reaches 1.7 million tons. It ranks third in nourishment crop speculation, after yam and cassava. It's increasing over the years. However, it exceeds the needs of the population; post-harvest losses remain high, amounting to $30 \%$ of production despite 
the expensive conservation methods used [2]. They constitute a socio-economic challenge for the country. The degradation of its starch contributes to this [3].

According to [4], the water content of plantain bananas exceeds $60 \%$ of their weight. It participates in its rapid alteration. For [5], it promotes $\mathrm{HB}$ with the hydroxyl of D-glucose, synthon of amylose or amylopectin; these are essential components of starch. The latter's degradation leads to the rotting of plantain bananas. However, these authors don't provide the modalities of interactions between water molecules and polysaccharides. Furthermore, [6] conjectured that, under the same conditions, amylopectin transforms less rapidly than amylose. This thesis allows understanding the starch's alteration process. The research proposes to test it.

This work aims to elucidate the mechanisms underlying the degradation of its starch's component. Specifically, using quantum chemistry methods, it plans to determine the main HB sites of the polysaccharides. Ultimately, it aspires to describe their mode of scission under the effect of water. It wants to contribute to the fight against the plantain bananas' degeneration. More, it proposes explaining the alteration's order of amylose or amylopectin. The article has two parts. It resumes and discusses the results. Before, it presents research methodology.

\section{Compounds and Calculation Methods}

This section presents the method of calculation. It elucidates the geometric, energetic and spectroscopic parameters used. Previously, it specifies the polysaccharide structure.

\subsection{The Polysaccharides}

Four (AM4G) and five (AM5G) D-glucose blocks represent amylose or amylopectin. They have three or four osidic bridges respectively (see Figure 1). Figure 1 illustrates the 3D molecular structure of AM4G, AMP4G, AM5G and AMP5G.

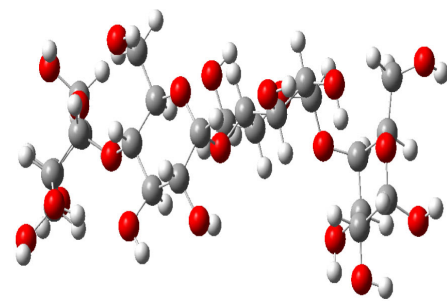

AM4G

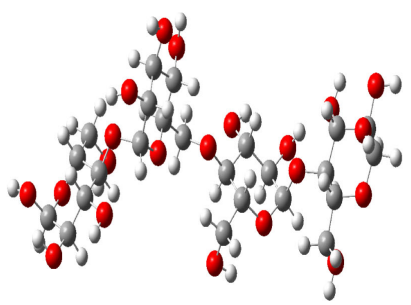

AMP4G

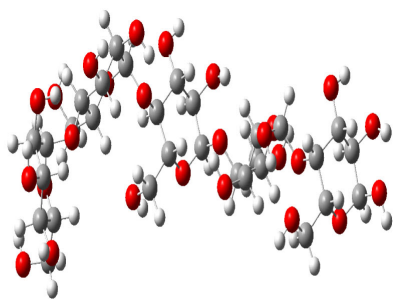

AM5G

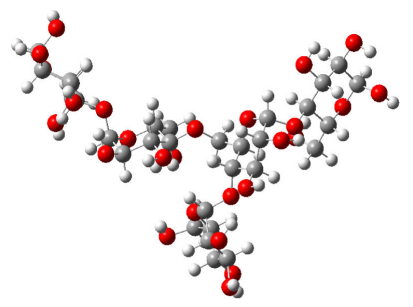

AMP5G

Figure 1. 3D image of the AM4G, AMP4G, AM5G and AMP5G. 
It comes from Gauss View 6.0. All oxygen atoms have sp3 hybridization. Red balls schematize them. They're numbered from 1 to 3 for four units of polysaccharides and from 1 to 4 for five ones. These labels also correspond to the names of the different $\mathrm{HB}$ complexes.

\subsection{Calculation Method}

The ONIOM (Our Own N-layered Integrated molecular Orbital and molecular Mechanics) developed by [7] suits here because of the atoms' large number of amylose or amylopectin. Figure 2 illustrates its principle. It consists of dividing AMG complexes into two entities. It computes these latter at different levels. The inner part corresponds to the surroundings where water interacts with D-glucose. It's calculated at a high-level B3LYP/6-311++G (d, p). Therefore, they allow describing HB precisely; the diffuse and polarization functions consider the isolated pairs of oxygen and their reactions with the hydrogen in the water.

The AM1 approach helps to capture the rest or the environment of the complex in a less rigorous way. Specifically, the ONIOM method provides energy from the high level of E polysaccharides (DFT, polysaccharides). To do this, ONIOM uses three other data. It calculates the energy of the complex at this same level $E$ (DFT, complex). AM1 estimates $E$ (AM1, complex) and $E$ (AM1, polysaccharides). Finally, $E$ (DFT, polysaccharides) gets with the formula:

$$
\begin{aligned}
& E(\mathrm{DFT}, \text { polysaccharides }) \\
& =E(\mathrm{AM} 1, \text { polysaccharides })+E(\mathrm{DFT}, \text { complex })-E(\mathrm{AM}, \text { complex })
\end{aligned}
$$

\subsection{Study Parameters}

This work uses three categories of parameters. These highlight the oxygen privileged to establish HB. The energies calculated also allow discussing on other orders of polysaccharides' degradation. The spectroscopic data contribute to validating the sites determined by the geometric of HB's characteristics.

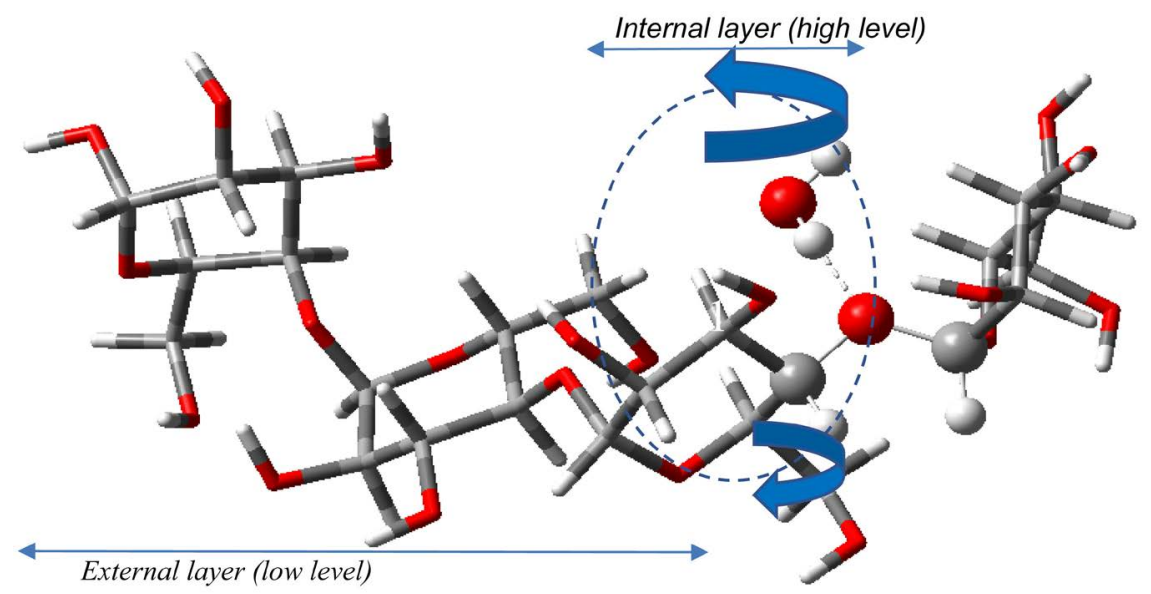

Figure 2. Calculation levels diagram of an AM4G complex according to the ONIOM method. 


\subsubsection{Geometric Parameters of $\mathrm{HB}$}

The complex gets from the connection of water's hydrogen to each oxygen of the Osidic Bridge. Three geometric quantities characterize HB (Figure 3). Before the optimization of the polysaccharides, the angle of linearity $\alpha$ is fixed at $180^{\circ}$. The oxygen hybridization state is sp3; $\beta$ is worth $109.5^{\circ}$ (Figure 4). Distance $d$ between this latter with hydrogen equals $2 \AA$. It corresponds to the minimum approach length of the two atoms [8].

According to [9], an HB is probable when the distance $d$ is less than the sum of the Van der Waals radii of oxygen (1.52 $)$ and hydrogen (1.1 $\AA$ ) [10] [11]; in these conditions, $d \leq 2.62 \AA$. HB becomes strong as d decreases; the preferred osidic site corresponding to its minimum value.

$\alpha$ is the linearity angle of the HB. It represents the space between the $\mathrm{O}-\mathrm{H}$ and Y-A bonds; $\mathrm{A}$ is the acceptor atom. $\beta$ is that of its direction. It's between Y-A and the axis of HB. The more $\alpha$ and $\beta$ deviate from the ideal values, the more this latter destabilizes. Here, a gap becomes significant if it's greater than $20^{\circ}$. Energy parameters also describe HB.

\subsubsection{Energy Parameters}

$\mathrm{HB}$ gets with reaction (2). The $\mathrm{Y}-\mathrm{A} \cdots \mathrm{H}-\mathrm{X}$ complex becomes its product.

$$
\mathrm{Y}-\mathrm{A}+\mathrm{H}-\mathrm{X} \rightarrow \mathrm{Y}-\mathrm{A} \cdots \mathrm{H}-\mathrm{X}
$$

Equation (3) gives the variation of energy at $0 \mathrm{~K}$ :

$$
\Delta E_{\text {elec }}^{0}=E_{\text {elec }}^{0}(\mathrm{Y}-\mathrm{A} \cdots \mathrm{H}-\mathrm{X})-\left[E_{\text {elec }}^{0}(\mathrm{Y}-\mathrm{A})+E_{\text {elec }}^{0}(\mathrm{H}-\mathrm{X})\right]
$$

The internal energy, at $298.15 \mathrm{~K}$, corresponds to the sum of the electronic, rotational, translational and vibrational ones. Equation (4) describes its variation.

$$
\Delta E_{298}^{0}=\Delta E_{\text {electronic }}^{0}+\Delta E_{\text {rotation }}^{0}+\Delta E_{\text {translation }}^{0}+\Delta E_{\text {vibration }}^{0}
$$

The optimization of reagent and product geometry gives access to all contributions (including nuclear repulsion). In the ideal approximation of perfect gas, Equation (5) provides the expressions of the translation or rotation energy.

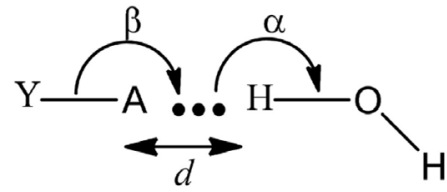

Figure 3. Geometric parameters $\alpha, \beta$ and $d$ of the HB [12].

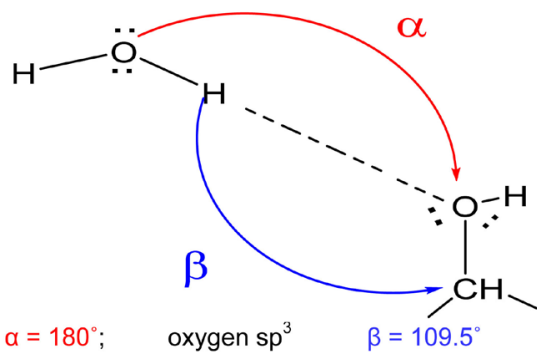

Figure 4. Linearity and direction angles of the HB. 


$$
\Delta E_{\text {translation }}^{0}=\Delta E_{\text {rotation }}^{0}=-3 / 2 R T
$$

$\Delta E_{\text {vibration }}^{\circ}$ includes ZPVE (Zero Point Vibrational Energy), that is, that of the lowest vibration level. $\Delta E_{\text {vibration }}^{\circ}$ generates normal vibration modes; generally, their number equals $3 \mathrm{~N}-6$. For a linear molecule, it becomes $3 \mathrm{~N}-5$ : at $0 \mathrm{~K}$, each at a frequency associated with the energy Equation (6):

$$
E_{\text {vib.thermal }}^{0}=R \sum_{i=1}^{3 N-6} \frac{h v_{i} / k}{\mathrm{e}^{h v_{i / 298 K}}-1}
$$

Consequently, Equation (7) allows calculating the internal energy variation of the reaction at $298.15 \mathrm{~K}$ :

$$
\Delta E_{298}^{0}=\Delta E_{\text {elec }}^{0}+\Delta Z P V E+\Delta E_{\text {vib.thermal }}^{0}-3 R T
$$

Equation (8) and Equation (9) give the enthalpy and free enthalpy variations for the following reactions at $298.15 \mathrm{~K}$.

$$
\begin{gathered}
\Delta H_{298 K}^{0}=\Delta E_{298 K}^{0}-R T \\
\Delta G_{298 K}^{0}=\Delta H_{298 K}^{0}-T \Delta S_{298 K}^{0} \\
\Delta S_{298 K}^{0}=\Delta S_{\text {trans }}^{0}+\Delta S_{\text {rot }}^{0}+\Delta S_{\text {vib }}^{0}
\end{gathered}
$$

Equation (10) corresponds to the variation in entropy under these conditions. More, spectroscopic parameters help to identify the sites of the liaison HB.

\subsubsection{Spectroscopic Parameters}

Spectroscopic descriptors can serve as a scale for HB. The strength of this latter depends on that of the $\mathrm{H}-\mathrm{X}$. Its stretching frequency remains accessible. When the donor is a water molecule, the displacement $\Delta \vartheta_{\mathrm{O}-\mathrm{H}}$ becomes the scale. For sp3, the Equation (11) defines this one:

$$
\Delta \vartheta_{\mathrm{O}-\mathrm{H}}=\vartheta_{\mathrm{Op}^{3} 3, \mathrm{H}, \mathrm{free}}-\vartheta_{\mathrm{O}_{\mathrm{sp}}{ }^{3}-\mathrm{H}, \mathrm{complex}}
$$

At the ONIOM level (B3LYP/6-311++G [d, p]: AM1), the vibrator frequency $\vartheta_{\mathrm{O}_{\mathrm{sp}}-\mathrm{H}, \mathrm{free}}$ is $3923.84 \mathrm{~cm}^{-1}$. If the value $\Delta \vartheta_{\mathrm{O}-\mathrm{H}}$ is positive, the frequency $\vartheta_{\mathrm{O}_{\mathrm{sp}}{ }^{3}-\mathrm{H}, \text { complex }}^{\mathrm{sp}^{3}}$ becomes lower than $\vartheta_{\mathrm{O}_{\mathrm{sp}}-\mathrm{H} \text {,free }}$; the frequency $\vartheta_{\mathrm{O}_{\mathrm{sp}^{3}}-\mathrm{H} \text {,free }}$ of the water decreases. Its hydrogen is approaching the oxygen of the Osidic Bridge. The more $\Delta \vartheta_{\mathrm{O}-\mathrm{H}}$ increases, the more likely it becomes an HB site. The article also presents and discusses the results of the research.

\section{Results and Discussion}

The geometric, energetic, and spectroscopic parameters come from all the calculations carried out on the different complexes. This work succeeds in optimizing all the geometries. Figure 5 and Figure 6 present respectively those obtained at ONIOM level (B3LYP/6-311++G [d, p]: AM1) for $A M 4 G-\mathrm{H}_{2} \mathrm{O}$ and AMP4G- $\mathrm{H}_{2} \mathrm{O}$.

\subsection{Study of the AM4G- $\mathrm{H}_{2} \mathrm{O}$ and $\mathrm{AMP} 4 \mathrm{G}-\mathrm{H}_{2} \mathrm{O}$ Complexes}

This part presents the associated results to the energy and spectroscopic quantities of AM4G- $\mathrm{H}_{2} \mathrm{O}$ and AMP4G- $\mathrm{H}_{2} \mathrm{O}$ complexes. Previously, it summarizes data related to geometric parameters. Table 1 explains them. 

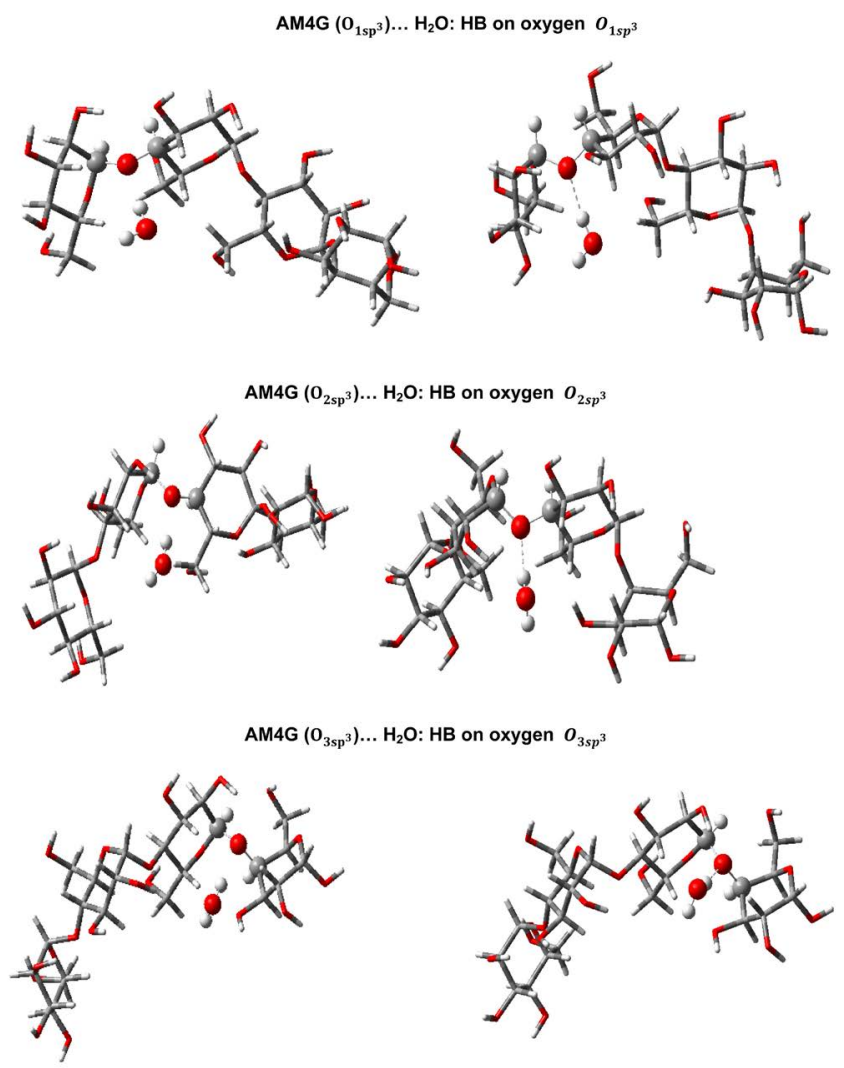

Figure 5. Initial (at left) and optimized (at right) geometries of the AM4G- $\mathrm{H}_{2} \mathrm{O}$ complex at the ONIOM level (B3LYP/6-311++G [d, p]: AM1).
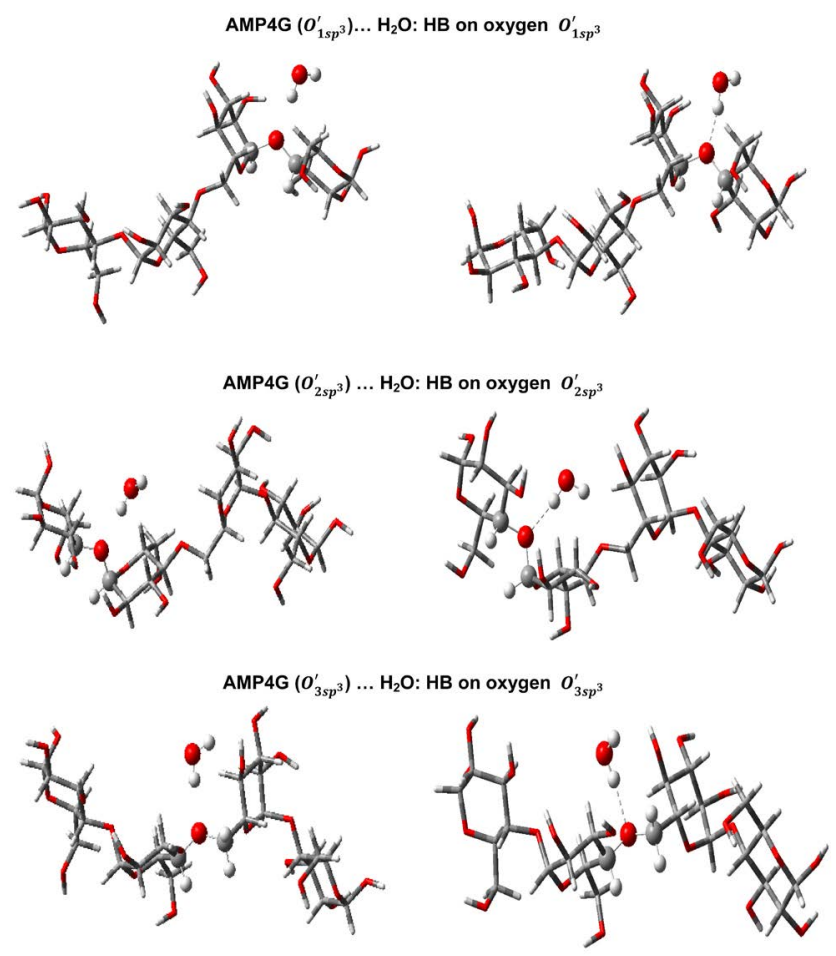

Figure 6. Initial (at left) and optimize (at right) geometries of AMP4G- $\mathrm{H}_{2} \mathrm{O}$ complex at ONIOM level (B3LYP/6-311++G [d, p]: AM1). 
Table 1. Geometric parameters of AM4G- $\mathrm{H}_{2} \mathrm{O}$ and AMP4G- $\mathrm{H}_{2} \mathrm{O}$ complexes at ONIOM level (B3LYP/6-311++G [d, p]: AM1).

\begin{tabular}{cccccccc}
\hline $\mathrm{AM} 4 \mathrm{G}$ & $\alpha\left({ }^{\circ}\right)$ & $\beta\left({ }^{\circ}\right)$ & $d(\AA)$ & $\mathrm{AMP} 4 \mathrm{G}$ & $\alpha\left({ }^{\circ}\right)$ & $\beta\left(^{\circ}\right)$ & $d(\AA)$ \\
\hline $\mathrm{O}_{1 \mathrm{sp}}$ & 172.55 & 112.62 & 1.92 & $\mathrm{O}_{1 \mathrm{sp} 3^{3}}$ & 168.01 & 117.24 & 1.96 \\
$\mathrm{O}_{2 \mathrm{sp}}$ & 168.22 & 108.47 & 1.84 & $\mathrm{O}_{2 \mathrm{sp}}$ & 171.24 & 125.33 & 1.96 \\
$\mathrm{O}_{3 \mathrm{sp}}$ & 159.27 & 118.5 & 1.88 & $\mathrm{O}_{3 \mathrm{sp}}$ & 167.64 & 109.55 & 1.83 \\
\hline
\end{tabular}

\subsubsection{Geometric Parameters of $\mathrm{HB}$}

Geometric parameters indicate that the three osidic oxygen establish HB with the hydrogen in water. All d values remain below $2.62 \AA$.

The linearity angles $\alpha$ and direction $\beta$ are close to $180^{\circ}$ and $109.5^{\circ}$ respectively. They suggest that all HB stay stable. However, $\mathrm{HB}$ is stronger with $\mathrm{O}_{2 \mathrm{sp}^{3}}$ in AM4G- $\mathrm{H}_{2} \mathrm{O}$ and $\mathrm{O}_{3 \mathrm{sp}^{3}}^{\prime}$ in AMP4G- $\mathrm{H}_{2} \mathrm{O}$. These two sites participate in solid $\mathrm{HB}$; they have the smallest values of the distance $d$. Ultimately, $\mathrm{O}_{2 \mathrm{sp}^{3}}$ is the main site of $\mathrm{HB}$ for $\mathrm{AM} 4 \mathrm{G}-\mathrm{H}_{2} \mathrm{O}$.

\subsubsection{Energy Parameters}

All enthalpies are negative; all HB formation processes are exothermic (Table 2). For the AM4G- $\mathrm{H}_{2} \mathrm{O}$ complex, its lowest value corresponds to $\mathrm{O}_{2 \mathrm{sp}^{3}}$. It goes down to $\Delta_{r} H_{298}^{\circ}=-7520 \mathrm{kcal} / \mathrm{mol}$. For AMP $4 \mathrm{G}-\mathrm{H}_{2} \mathrm{O}$, its lowest value corresponds to $\mathrm{O}_{2 \mathrm{sp}^{3}}^{\prime}$ the enthalpy decreases to $\Delta_{r} H_{298}^{\circ}=-7122 \mathrm{kcal} / \mathrm{mol}$. It's not far from $\Delta_{r} H_{298}^{\circ}=-7050 \mathrm{kcal} / \mathrm{mol}$; in this case, $\mathrm{O}_{3 \mathrm{sp}{ }^{\prime}}$ is another site.

The positive values of the free enthalpies $\Delta_{r} G_{298}^{\circ}$ suggest that the reaction be spontaneous. At the same time, its weakest ones come from oxygen $\mathrm{O}_{2 \mathrm{sp}}$ especially with $\Delta_{r} G_{298}^{\circ}=1709 \mathrm{kcal} / \mathrm{mol}$ for AM4G- $\mathrm{H}_{2} \mathrm{O}$. In the case of AMP4G- $\mathrm{H}_{2} \mathrm{O}$, $\mathrm{O}_{3 \mathrm{sp}^{3}}^{\prime}$ has the lowest free enthalpy with $\Delta_{r} G_{298}^{\circ}=2688 \mathrm{kcal} / \mathrm{mol}$.

Spontaneity is much greater with $\mathrm{O}_{2 \mathrm{sp}^{3}}$ and $\mathrm{O}_{3 \mathrm{sp}^{3}}^{\prime}$; their free enthalpies are the lowest. Therefore, $\mathrm{O}_{2 \mathrm{sp}^{3}}$ and $\mathrm{O}_{3 \mathrm{sp}}^{\prime}{ }^{3}$ are the main $\mathrm{HB}$ sites for respective AM4G and AMP4G. This result confirms that of regarding the geometric parameters' analysis. More,

$$
\Delta_{r} G_{298}^{\circ}\left(\mathrm{O}_{2 \mathrm{sp}^{3}}\right)<\Delta_{r} G_{298}^{\circ}\left(\mathrm{O}_{3 \mathrm{sp}^{3}}^{\prime}\right)
$$

This inequality (12) means that AM4G degrades faster than AMP4G. This assertion is in line with the hypothesis of [6]; the amylopectin's deterioration is slower than that of the amylose.

\subsubsection{Spectroscopic Parameters}

The spectroscopic descriptors are conceived as elements of a basicity scale of $\mathrm{HB}$. Each shift of frequencies between free $\mathrm{OH}$ bands associated with water is linked to an energy of the HB (Badger and Bauer, 1937 cited by [13]). They make it possible to characterize the resistance of $\mathrm{HB}$ to its elongation. The greater is the offset, the stronger is the HB. 
Table 2. Energy parameters (in $\mathrm{kcal} / \mathrm{mol}$ ) of $\mathrm{AM} 4 \mathrm{G}-\mathrm{H}_{2} \mathrm{O}$ and $\mathrm{AMP} 4 \mathrm{G}-\mathrm{H}_{2} \mathrm{O}$ complexes, entropy (in $\mathrm{cal} / \mathrm{mol} \cdot \mathrm{K}^{-1}$ ).

\begin{tabular}{cccccccc}
\hline $\mathrm{AM} 4 \mathrm{G}-\mathrm{H}_{2} \mathrm{O}$ & $\Delta_{r} H_{298}^{\circ}$ & $\Delta_{r} S_{298}$ & $\Delta_{r} G_{298}^{\circ}$ & AMP4G- $\mathrm{H}_{2} \mathrm{O}$ & $\Delta_{r} H_{298}^{\circ}$ & $\Delta_{r} S_{298}$ & $\Delta_{r} G_{298}^{\circ}$ \\
\hline $\mathrm{O}_{1 \mathrm{sp}^{3}}$ & -6.983 & -34.600 & 3.334 & $\mathrm{O}_{1 \mathrm{sp}}$ & -5.119 & -30.867 & 4.084 \\
$\mathrm{O}_{2 \mathrm{sp}^{3}}$ & -7.520 & -30.976 & 1.709 & $\mathrm{O}_{2 \mathrm{sp}}$ & -7.122 & -35.956 & 3.598 \\
$\mathrm{O}_{3 \mathrm{sp}^{3}}$ & -7.072 & -35.374 & 3.475 & $\mathrm{O}_{3 \mathrm{sp}}$ & -7.050 & -32.661 & 2.688 \\
\hline
\end{tabular}

All the values of the frequency shifts $\Delta \vartheta_{\mathrm{O}-\mathrm{H}}$ are positive. The highest values correspond to the heteroatoms $\mathrm{O}_{1 \mathrm{sp}}{ }^{3}$ and $\mathrm{O}_{3 \mathrm{sp}^{3}}^{\prime}$ of AM4G and AMP4G, respectively. The associated wave numbers are $281.45 \mathrm{~cm}^{-1}$ and $267.37 \mathrm{~cm}^{-1}$. The spectroscopic parameters suggest that the oxygen $\mathrm{O}_{2 \mathrm{sp}^{3}}$ and $\mathrm{O}_{3 \mathrm{sp}^{3}}^{\prime}$ become the main sites for HB. Examination of the geometric, energetic and spectroscopic parameters establishes that $\mathrm{O}_{2 \mathrm{sp}^{3}}$ and $\mathrm{O}_{3 \mathrm{sp}^{3}}^{\prime}$ are the preferred $\mathrm{HB}$ receptors for the AM4G and AMP4G polysaccharides respectively (Table 3).

However, variations in enthalpies at $298.15 \mathrm{~K}$ indicate that $\mathrm{O}_{2 \mathrm{sp}^{3}}^{\prime}$ oxygen may also become the preferred receptor for AMP4G. Free enthalpies of formation elucidate polysaccharides' alteration order. Their values prove that the AM4G molecule degrades before AMP4G.

\subsection{Study of the AM5G- $\mathrm{H}_{2} \mathrm{O}$ and $\mathrm{AMP} 5 \mathrm{G}-\mathrm{H}_{2} \mathrm{O}$ Complexes}

This section concerns the results relating to the energy and spectroscopic parameters of the AM5G- $\mathrm{H}_{2} \mathrm{O}$ and $\mathrm{AMP} 5 \mathrm{G}-\mathrm{H}_{2} \mathrm{O}$ complexes. It introduces and discusses them. It also details those of the geometry. Table 4 summarizes them.

\subsubsection{Geometric Parameters}

This work optimizes the geometries of all complexes. Two of them geometric parameters confirm that the four oxygen of the osidic bridges establish HB with the hydrogen of water. All d values are less than $2.62 \AA$. Linearity and direction angles remain close to $180^{\circ}$ and $109.5^{\circ}$. They suggest that all HB stay stable. However, $\mathrm{O}_{2 \mathrm{sp}^{3}}$ of the AM5G and $\mathrm{O}_{4 \mathrm{sp}^{3}}^{\prime}$ of the AMP4G participate strongly. These two sites have the lowest $\mathrm{d}$ distances. In short, $\mathrm{O}_{2 \mathrm{sp}^{3}}$ is the oxygen of $\mathrm{HB}$ for AM5G- $\mathrm{H}_{2} \mathrm{O}$ while $\mathrm{O}_{4 \mathrm{sp}}^{\prime}$ becomes that of AMP4G- $\mathrm{H}_{2} \mathrm{O}$.

\subsubsection{Energy Parameters}

The energetic parameters make it possible to characterize a complex's formation or study the energy exchanges during this process. Table 5 presents those of the AM5G- $\mathrm{H}_{2} \mathrm{O}$ and AM5PG- $\mathrm{H}_{2} \mathrm{O}$. The enthalpies $\Delta_{r} H_{298}^{\circ}$ stay negative; HB's creation reaction remains exothermic. However, for AM5G- $\mathrm{H}_{2} \mathrm{O}$, the lowest value gets for $\mathrm{O}_{4 \mathrm{sp}^{3}}$. It's equivalent to $\Delta_{r} H_{298}^{\circ}=-89,390 \mathrm{kcal} / \mathrm{mol}$. It differs only slightly from $\Delta_{r} H_{298}^{\circ}=-8251 \mathrm{kcal} / \mathrm{mol} ; \mathrm{O}_{2 \mathrm{sp}^{3}}$ becomes the second most favourable site for $\mathrm{HB}$. For the AMP5G- $\mathrm{H}_{2} \mathrm{O}$ complex, the smallest enthalpy is then $\Delta_{r} H_{298}^{\circ}=-8111 \mathrm{kcal}$. It corresponds to $\mathrm{O}_{4 \mathrm{sp}^{3}}^{\prime}$. In this case, the latter constitutes the privileged site of $\mathrm{HB}$. 
Table 3. Displacement frequencies $\Delta \vartheta_{\mathrm{O}-\mathrm{H}}\left(\mathrm{cm}^{-1}\right)$ of the AM4G- $\mathrm{H}_{2} \mathrm{O}$ andAMP4G- $\mathrm{H}_{2} \mathrm{O}$ complexes.

\begin{tabular}{cccc}
\hline $\mathrm{AM} 4 \mathrm{G}$ & $\Delta \vartheta_{\mathrm{O}-\mathrm{H}}\left(\mathrm{cm}^{-1}\right)$ & $\mathrm{AMP} 4 \mathrm{G}$ & $\Delta \vartheta_{\text {O-H }}\left(\mathrm{cm}^{-1}\right)$ \\
\hline $\mathrm{O}_{1 \mathrm{sp}}$ & 260.96 & $\mathrm{O}_{1 \mathrm{sp}}$ & 266.19 \\
$\mathrm{O}_{2 \mathrm{sp}}$ & 281.45 & $\mathrm{O}_{2 \mathrm{sp}}$ & 242.78 \\
$\mathrm{O}_{3 \mathrm{sp}}$ & 280.11 & $\mathrm{O}_{3 \mathrm{sp}}$ & 267.37 \\
\hline
\end{tabular}

Table 4. Geometric parameters of AM5G- $\mathrm{H}_{2} \mathrm{O}$ and AMP5G- $\mathrm{H}_{2} \mathrm{O}$ complexes at ONIOM level (B3LYP/6-311++G [d, p]: AM1).

\begin{tabular}{cccccccc}
\hline AM5G & $\alpha\left({ }^{\circ}\right)$ & $\beta\left(^{\circ}\right)$ & $d(\AA)$ & AMP5G & $\alpha\left(^{\circ}\right)$ & $\beta\left(^{\circ}\right)$ & $d(\AA)$ \\
\hline $\mathrm{O}_{1 \mathrm{sp}}$ & 172.57 & 126.63 & 1.92 & $\mathrm{O}_{1 \mathrm{sp}^{3}}$ & 173.05 & 128.55 & 1.85 \\
$\mathrm{O}_{2 \mathrm{sp}}$ & 169.27 & 108.08 & 1.84 & $\mathrm{O}_{2 \mathrm{ps}^{3}}$ & 167.81 & 117.05 & 1.86 \\
$\mathrm{O}_{3 \mathrm{sp}^{3}}$ & 159.37 & 114.09 & 1.87 & $\mathrm{O}_{3 \mathrm{sp}^{3}}$ & 169.81 & 120.76 & 1.94 \\
$\mathrm{O}_{4 \mathrm{sp}}$ & 168.59 & 113.11 & 1.87 & $\mathrm{O}_{4 \mathrm{sp}}$ & 170.99 & 112.3 & 1.83 \\
\hline
\end{tabular}

Table 5. Energetics parameters (in $\mathrm{kcal} / \mathrm{mol}$ ) of $\mathrm{AM} 4 \mathrm{G}-\mathrm{H}_{2} \mathrm{O}$ and $\mathrm{AMP} 4 \mathrm{G}-\mathrm{H}_{2} \mathrm{O}$ complexes-entropy (in $\mathrm{cal} / \mathrm{mol} \mathrm{K}$ ).

\begin{tabular}{cccccccc}
\hline $\mathrm{AM} 5 \mathrm{G}-\mathrm{H}_{2} \mathrm{O}$ & $\Delta_{r} H_{298}^{\circ}$ & $\Delta_{r} S_{298}$ & $\Delta_{r} G_{298}^{\circ}$ & AMP5G-H $2 \mathrm{O}$ & $\Delta_{r} H_{298}^{\circ}$ & $\Delta_{r} S_{298}$ & $\Delta_{r} G_{298}^{\circ}$ \\
\hline $\mathrm{O}_{1 \mathrm{sp}}$ & -7.025 & -34.591 & 3.288 & $\mathrm{O}_{1 \mathrm{sp}}$ & -7.089 & -35.067 & 3.367 \\
$\mathrm{O}_{2 \mathrm{sp}}$ & -8.251 & -29.593 & 1.164 & $\mathrm{O}_{2 \mathrm{sp}^{3}}$ & -5.510 & -30.374 & 3.546 \\
$\mathrm{O}_{3 \mathrm{sp}}$ & -7.084 & -35.316 & 3.364 & $\mathrm{O}_{3 \mathrm{sp}^{3}}$ & -6.263 & -32.373 & 3.389 \\
$\mathrm{O}_{4 \mathrm{sp}}$ & -8.939 & -36.279 & 1.878 & $\mathrm{O}_{4 \mathrm{sp}^{3}}$ & -8.111 & -33.494 & 1.876 \\
\hline
\end{tabular}

The positive values of the free enthalpy $\Delta_{r} G_{298}^{\circ}$ show that complexation reaction isn't spontaneous. However, its lowest one comes from the sites $\mathrm{O}_{2 \mathrm{sp}^{3}}$ $\left(\Delta_{r} G_{298}^{\circ}=1164 \mathrm{kcal} / \mathrm{mol}\right)$ and $\mathrm{O}_{4 \mathrm{sp}^{3}}\left(\Delta_{r} G_{298}^{\circ}=1878 \mathrm{kcal} / \mathrm{mol}\right)$ for AM5G. In the case of AMP5G, $\mathrm{O}_{4 \mathrm{sp}^{3}}$ has the smaller $\Delta_{r} G_{298}^{\circ}=1876 \mathrm{kcal} / \mathrm{mol}$.

Spontaneity is much greater with $\mathrm{O}_{2 \mathrm{sp}^{3}}$ and $\mathrm{O}_{4 \mathrm{sp}^{3}}$ for $\mathrm{AM} 5 \mathrm{G}-\mathrm{H}_{2} \mathrm{O}$ and with $\mathrm{O}_{4 \mathrm{sp}^{3}}^{\prime}$ for AMP5G- $\mathrm{H}_{2} \mathrm{O}$; the free enthalpies at these sites are the lowest. The first two are the main receptors of $\mathrm{HB}$ for $\mathrm{AM} 5 \mathrm{G}-\mathrm{H}_{2} \mathrm{O}$ and the third one of AMP5G- $\mathrm{H}_{2} \mathrm{O}$. This result confirms the conclusion obtained with $\mathrm{O}_{2 \mathrm{sp}^{3}}$ and $\mathrm{O}_{4 \mathrm{sp}^{3}}^{\prime}$ from the geometric parameters. Furthermore,

$$
\Delta_{r} G_{298}^{\circ}\left(\mathrm{O}_{2 \mathrm{sp}^{3}}\right)<\Delta_{r} G_{298}^{\circ}\left(\mathrm{O}_{4 \mathrm{sp}^{3}}^{\prime}\right)
$$

This inequality (13) means that AM5G degrades before AMP5G. It proves that amylose transforms faster than amylopectin. It remains consistent with the thesis of [6].

\subsubsection{Spectroscopic Parameters}

Table 6 presents displacement frequencies $\Delta \vartheta_{\mathrm{O}-\mathrm{H}}$ of the $\mathrm{AM} 4 \mathrm{G}-\mathrm{H}_{2} \mathrm{O}$ and 
Table 6. Displacement frequencies $\Delta \vartheta_{\mathrm{O}-\mathrm{H}}\left(\mathrm{cm}^{-1}\right)$ of the AM4G- $\mathrm{H}_{2} \mathrm{O}$ and AMP4G- $\mathrm{H}_{2} \mathrm{O}$ complexes.

\begin{tabular}{cccc}
\hline AM5G & $\Delta \vartheta_{\mathrm{O}-\mathrm{H}}\left(\mathrm{cm}^{-1}\right)$ & AMP5G & $\Delta \vartheta_{\mathrm{O}-\mathrm{H}}\left(\mathrm{cm}^{-1}\right)$ \\
\hline $\mathrm{O}_{1 \mathrm{sp}^{3}}$ & 261.07 & $\mathrm{O}_{1 \mathrm{sp}^{3}}$ & 278.61 \\
$\mathrm{O}_{2 \mathrm{sp}^{3}}$ & 284.36 & $\mathrm{O}_{2 \mathrm{sp}^{3}}$ & 307.57 \\
$\mathrm{O}_{3 \mathrm{sp}^{3}}$ & 280.52 & $\mathrm{O}_{3 \mathrm{sp}^{3}}$ & 251.51 \\
$\mathrm{O}_{4 \mathrm{sp}^{3}}$ & 264.66 & $\mathrm{O}_{4 \mathrm{sp}^{3}}$ & 343.08 \\
\hline
\end{tabular}

AMP4G- $\mathrm{H}_{2} \mathrm{O}$ complexes at the ONIOM level (B3LYP/6-311++G [d, p]: AM1). The vibrator frequency $\vartheta_{\mathrm{O}_{\mathrm{sp}}{ }^{3} \text {-H,free }}$ is $3923.84 \mathrm{~cm}^{-1}$. If the value $\Delta \vartheta_{\mathrm{O}-\mathrm{H}}$ is positive, the frequency $\vartheta_{\mathrm{O}^{3} \text {-H,complex }}$ becomes lower than $\vartheta_{\mathrm{Osp}^{3}-\mathrm{H}, \text { libre }}$; the frequency $\vartheta_{\mathrm{O}_{\mathrm{sp}^{3}}-\mathrm{H}, \mathrm{libre}}$ of the water decreases. Its hydrogen is approaching the oxygen of the Osidic Bridge, the more $\Delta \vartheta_{\mathrm{OH}}$ increases, the more this site becomes likely to favour HB. All frequency shifts $\Delta \vartheta_{\mathrm{O}-\mathrm{H}}$ have positive values. The highest one refers $\mathrm{O}_{2 \mathrm{sp}^{3}}$ and $\mathrm{O}_{4 \mathrm{sp}}^{\prime}$ for respective AM5G and AMP5G. The associated wave numbers are $284.36 \mathrm{~cm}^{-1}$ and $343.08 \mathrm{~cm}^{-1}$. Spectroscopic data suggest that $\mathrm{O}_{2 \mathrm{sp}^{3}}^{\prime}$ and $\mathrm{O}_{4 \mathrm{sp}^{3}}^{\prime}$ are the main sites for $\mathrm{HB}$.

The analysis of geometric, energetic and spectroscopic parameters at the ONIOM level (B3LYP/6-311++G [d, p]: AM1) shows that the oxygen of the osidic bridge $\mathrm{O}_{2 \mathrm{sp}^{3}}$ and $\mathrm{O}_{4 \mathrm{sp}^{3}}^{\prime}$ are respectively the preferred receptors to establish a HB with water's molecule. However, the enthalpies indicate that the oxygen $\mathrm{O}_{4 \mathrm{sp}}{ }^{3}$ is another receptor in the AM5G. Free enthalpies of formation's examination elucidate the order of the polysaccharides' alteration. It proves that the AM5G molecule degrades before AMP5G.

Moreover, the lengthening of the chain doesn't influence on the behavior of amylose. $\mathrm{O}_{2 \mathrm{sp}}$ remains the most favourable site to realize HB. The additional D-glucose of AM5G doesn't impact its transformation sequence. This polysaccharide always changes first. It disintegrates into disaccharides. On the other hand, this situation modifies the water anchor point for amylopectin. It moves its preferred receptor $\mathrm{O}_{3 \mathrm{sp}^{3}}^{\prime}$ to $\mathrm{O}_{4 \mathrm{sp}^{3}}^{\prime}$. This hypothesis deserves to be verified in next work. It leads us to conclude this article.

\section{Conclusions}

This research aims to describe the modalities of the polysaccharides' alteration in the presence of water molecules. To do this, it uses reduced chains of amylose or amylopectin at four and five D-glucose synthons. It employs the two-layer ONIOM method at the ONIOM level (B3LYP/6-311++G [d, p]: AM1). Its calculations generate the geometric, energetic, and spectroscopic parameters related to the polysaccharide-water complexes. These data enable the definition of the main sites of the HB.

Oxygen $\mathrm{O}_{2 \mathrm{sp}^{3}}$ and $\mathrm{O}_{3 \mathrm{sp}^{3}}^{\prime}$ constitute, at $298.15 \mathrm{~K}$, respectively the preferred HB receptors for polysaccharides with four D-glucose (AM4G and AMP4G). 
$\mathrm{O}_{2 \mathrm{sp}^{3}}$ and $\mathrm{O}_{4 \mathrm{sp}^{3}}^{\prime}$ are for those with five synthons (AM5G and AMP5G). Furthermore, research shows that amylose degrades before amylopectin. The lengthening of the synthon's chain has little influence on its behavior. $\mathrm{O}_{2 \mathrm{sp}^{3}}$ remains the most favourable receptor for establishing an HB; however, an additional D-glucose changes the site of amylopectin. This one moves from $\mathrm{O}_{3 \mathrm{sp}^{3}}^{\prime}$ to $\mathrm{O}_{4 \mathrm{sp}^{3}}^{\prime}$. This result makes it possible to propose a mechanism for degrading starch.

The water breaks down the amylose into disaccharides. It then splits the amylopectin into tri-saccharides for AM4G or AMP4G and into tetra-saccharides for AM5G and AMP5G. It also suggests that its alteration can occur with higher rank oxygen of a polysaccharide future work that can test this last hypothesis. In addition, this result makes it possible to suggest avenues for avoiding the degradation of the mono to the pent saccharide. It promotes the establishment of a protocol to sustainably protect the sensitive site.

\section{Conflicts of Interest}

The authors declare no conflicts of interest regarding the publication of this paper.

\section{References}

[1] Assemand, E., Fatoumata, C., Françoise, K., Victorien, K. and Lucien, P.K. (2012) Caractérisation biochimique des fruits de plantain (Musa paradisiaca L.) variété agnrin de Côte d'Ivoire et évaluation sensasorielle de ses produits dérivés. Journal of Applied Biosciences, 60, 4438-4447.

[2] Yao, K.A., Djary, M.K., Zaouli, B.I. and Sébastien, L.N. (2014) Effet de la substitution partielle de la farine de blé par lapurée de banane plantain (Musa AAB) bien mûre sur la qualité des produits de pâtisserie. Journal of Applied Biosciences, 82, 7436-7448. https://doi.org/10.4314/jab.v82i1.12

[3] Cordenunsi, B. and Lajolo, F. (1995) Starch Breakdown during Banana Ripening: Sucrose Synthase and Sucrose Phosphate Synthase. Journal of Agricultural and Food Chemistry, 43, 363-372. https://doi.org/10.1021/jf00050a016

[4] FIRCA (2010) Répertoire de technologies de conservation et de transformation de l'igname et de la banane plantain. Fonds Interprofessionnel pour la Recherche et le Conseil Agricoles. Groupe le Prestige. Cocody, Abidjan.

[5] Momany, F.A., Appell, M., Strati, G. and Willett, J.L. (2004) B3LYP/6-311++G** Study of Monohydrates of a- and b-D-Glucopyranose: Hydrogen Bonding, Stress Energies, and Effect of Hydration on Internal Coordinates. Carbohydrate Research, 339, 553-567. https://doi.org/10.1016/j.carres.2003.10.013

[6] Kurt, M. and Gonon, W.F. (1951) La degradation de l'amylopectine par les alpha-amylases. Recherches sur l'amidon 51. Helvetica Chimica Acta, 34, 308-316. https://doi.org/10.1002/hlca.19510340134

[7] Vreven, T. and Morokuma, K. (2000) On the Application of the IMOMO (Integrated Molecular Orbital + Molecular Orbital) Method. Journal of Computational Chemistry, 21, 1419-1432. https://doi.org/10.1002/1096-987X(200012)21:16<1419::AID-JCC1>3.0.CO;2-C

[8] Jeffrey, G.A. and Saenger, W. (1991) Hydrogen Bonding in Biological Structures. 
Springer, Berlin. https://doi.org/10.1007/978-3-642-85135-3

[9] Rowland, R.S. and Taylor, R. (1996) Intermolecular Nonbonded Contact Distances in Organic Crystal Structures: Comparison with Distances Expected from van der Waals Radii. Journal of Physical Chemistry, 100, 7384-7391.

https://doi.org/10.1021/jp953141+

[10] Jorly, J. and Eluvathingal, D.J. (2007) Red-, Blue-, or No-Shift in Hydrogen Bonds: A Unified Explanation. Journal of the American Chemical Society, 129, 4620-4632. https://doi.org/10.1021/ja067545z

[11] Bondi, A. (1964) Van der Waals Volumes and Radii. Journal of Physical Chemistry, 68, 441-451. https://doi.org/10.1021/j100785a001

[12] Desiraju, G. and Steiner, T. (1999) The Weak Hydrogen Bond in Structural Chemistry and Biology. Oxford University Press, Oxford.

[13] Graton, J. (2001) Basicité des Amines et de Nicotines: Liaison Hydrogène et Protonation. Thèse de doctorat, Université de Nantes, Nantes. 